\title{
On the Proliferation Potential of Uranium Fuel for Research Reactors at Various Enrichment Levels
}

\section{Alexander Glaser}

Program on Science and Global Security, Princeton University, Princeton, NJ, USA

This article reviews the rationale of selecting an enrichment of just less than $20 \%$ (lowenriched uranium) as the preferred enrichment level for research reactor fuel in order to minimize overall proliferation risks. The net strategic value of the nuclear material associated with reactor operation is evaluated for a variety of enrichment levels, ranging from slightly enriched to weapon-grade fuel. To quantify the proliferation potential, both the demand of fresh uranium fuel as well as the plutonium buildup in the irradiated fuel are estimated via cell burnup calculations. The analysis confirms the usefulness of the current enrichment limit and challenges a recent trend to reconsider fuel enrichment levels between $20 \%$ and $50 \%$ for new research reactor projects.

\section{INTRODUCTION}

The operation of research reactors is linked to a series of proliferation risks, which are primarily associated with the fuel required to operate the facility. From a technical perspective, two complementary pathways have to be evaluated. ${ }^{1,2}$

- Diversion or Theft of Highly Enriched Uranium

Using highly enriched uranium (HEU) to fuel research reactors directly leads to a set of inevitable and obvious proliferation risks that are associated with diversion or theft of the material. For this reason, the conversion of research reactors to low-enriched fuel has been pursued since the late 1970s. Uranium used in HEU-fueled research reactors is typically enriched to more than $90 \%$ (weapon-grade uranium, WGU), but any uranium composition

Received 2 June 2005; accepted 27 September 2005.

Address correspondence to Alexander Glaser, Program on Science and Global Security, Princeton University, 221 Nassau Street, Princeton, NJ 08542, USA. E-mail: aglaser@ princeton.edu 
with a U-235 content of at least $20 \%$ is formally classified as direct-use material.

More generally, pre-enriched uranium, contained in the fresh or recovered from the spent fuel, could also be used as a feed-stock to produce weapongrade HEU if a small enrichment capacity is available to the proliferator.

- Production of Plutonium

The lower the enrichment level of any uranium-based nuclear fuel, the higher the plutonium buildup via neutron capture in uranium-238. In fact, plutonium production becomes the leading proliferation concern for reactors fueled with natural or slightly enriched uranium, while the uranium itself becomes rather unattractive.

It is intuitively clear that it should be possible to identify an optimum uranium composition that suppresses plutonium buildup as far as possible while keeping the initial uranium fuel unattractive for use in a nuclear weapon or explosive device. ${ }^{3}$ Historically, this limit has been set at an enrichment of just less than $20 \%$, but the adequacy of this conversion goal for research reactors is by no means obvious. Detailed, albeit still idealized, scenarios for the operation of a generic 30 MW MTR-type research reactor are therefore defined and evaluated below. ${ }^{4}$ Before turning to this analysis, the definitions of low-enriched and highly enriched uranium are briefly introduced and some weapon-relevant characteristics of uranium discussed.

\section{LOW-ENRICHED VERSUS HIGHLY ENRICHED URANIUM}

Two major uranium isotopes occur naturally in appreciable concentrations. These are uranium-238 and uranium-235, with isotopic fractions of $99.29 \%$ and $0.71 \%$, respectively. ${ }^{5}$ The enrichment, i.e., the weight fraction of U-235, determines the main characteristics of any uranium composition both with respect to its performance as reactor fuel or as fissile material in a nuclear weapon. Below a certain enrichment limit, weapon designers attest that the construction of a nuclear weapon or explosive device becomes impractical. For this reason, low-enriched uranium (LEU) and highly enriched uranium (HEU) have been introduced.

The concept of LEU was first used by some U.S. National Laboratories and the U.S. Atomic Energy Commission in or prior to $1955 .{ }^{6}$ The same convention was later also adopted by the International Atomic Energy Agency (IAEA), which defines low-enriched uranium as "enriched uranium containing less than $20 \%$ of the isotope ${ }^{235} \mathrm{U} .{ }^{77}$ Likewise, the IAEA classifies LEU as a so-called indirect use material, which in turn is defined as a nuclear material that cannot be 
used for "the manufacture of nuclear explosive devices without transmutation or further enrichment."

\section{CHARACTERISTICS OF ENRICHED URANIUM RELEVANT TO ITS WEAPON-USABILITY}

The following discussion summarizes some important characteristics of enriched uranium that are relevant in the context of its weapon-usability. Two main aspects are discussed: these are the critical mass and the neutron emission rate of uranium of a given composition. These considerations clearly demonstrate the fundamental difference between highly enriched and low-enriched uranium.

\section{Critical Mass}

The critical mass of a nuclear material is one important property of the material with respect to its weapon-usability. By definition, a critical mass is the amount of material in a defined configuration that is required to maintain a self-sustaining neutron chain reaction. In general, the critical mass represents a reasonable estimate of the amount of material required to construct a nuclear weapon or explosive device using material of a given composition.

Figure 1 shows the critical mass of a beryllium-reflected uranium sphere as a function of uranium-235 enrichment. The reflector thickness is $15 \mathrm{~cm}$

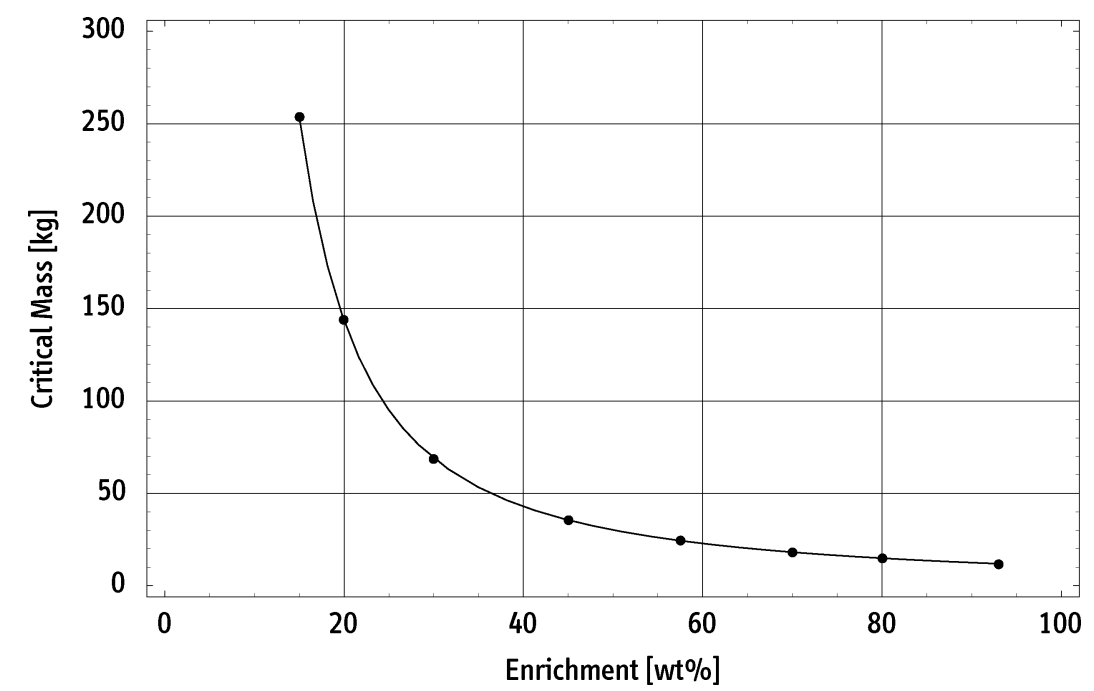

Figure 1: Critical mass of a beryllium-reflected uranium sphere as a function of the uranium-235 enrichment. MCNP 4C simulations at $300 \mathrm{~K}$ using ENDF/B-VI cross-section libraries. Reflector thickness is $15 \mathrm{~cm}$. Assumed value of uranium density is $19 \mathrm{~g} / \mathrm{cm}^{3}$. Enrichment is given in weight percent (wt\%) for a simple binary mixture of U-235 and U-238. 
Table 1: Critical masses of uranium at various enrichment levels and thicknesses of the beryllium reflector MCNP $4 \mathrm{C}$ calculations at $300 \mathrm{~K}$ using ENDF/B-VI cross-section libraries. Uranium compositions are assumed to be binary mixtures of U-235 and U-238. Values for reactor-grade, fuel-grade, and weapon-grade plutonium are included for reference purposes. ${ }^{9}$ Uranium and plutonium densities are both fixed at $19.0 \mathrm{~g} / \mathrm{cc}$. Note that plutonium may need to be stabilized in the $\delta$-phase, which is characterized by a lower density of the metal.

\begin{tabular}{|c|c|c|c|c|}
\hline \multirow[t]{2}{*}{ Uranium enrichment } & \multicolumn{4}{|c|}{ Reflector thickness } \\
\hline & Bare & $5 \mathrm{~cm}$ & $10 \mathrm{~cm}$ & $15 \mathrm{~cm}$ \\
\hline $10 w+\%$ & Very large & Very large & $\begin{array}{l}1435.0 \mathrm{~kg} \\
(\varnothing 52.4 \mathrm{~cm})\end{array}$ & $\begin{array}{c}753.0 \mathrm{~kg} \\
(\varnothing 42.3 \mathrm{~cm})\end{array}$ \\
\hline $15 w+\%$ & $\begin{array}{l}1351.0 \mathrm{~kg} \\
(\varnothing 51.4 \mathrm{~cm})\end{array}$ & $\begin{array}{c}758.3 \mathrm{~kg} \\
(\varnothing 42.4 \mathrm{~cm})\end{array}$ & $\begin{array}{c}426.5 \mathrm{~kg} \\
(\varnothing 35.0 \mathrm{~cm})\end{array}$ & $\begin{array}{c}253.8 \mathrm{~kg} \\
(\varnothing 29.4 \mathrm{~cm})\end{array}$ \\
\hline $19.75 w+\%$ & $\begin{array}{c}782.2 \mathrm{~kg} \\
(\varnothing 42.8 \mathrm{~cm})\end{array}$ & $\begin{array}{c}402.9 \mathrm{~kg} \\
(\varnothing 34.3 \mathrm{~cm})\end{array}$ & $\begin{array}{c}220.7 \mathrm{~kg} \\
(\varnothing 28.1 \mathrm{~cm})\end{array}$ & $\begin{array}{c}143.8 \mathrm{~kg} \\
(\varnothing 24.4 \mathrm{~cm})\end{array}$ \\
\hline $30 w+\%$ & $\begin{array}{c}367.4 \mathrm{~kg} \\
(\varnothing 33.3 \mathrm{~cm})\end{array}$ & $\begin{array}{c}171.2 \mathrm{~kg} \\
(\varnothing 25.8 \mathrm{~cm})\end{array}$ & $\begin{array}{c}100.3 \mathrm{~kg} \\
(\varnothing 21.6 \mathrm{~cm})\end{array}$ & $\begin{array}{c}68.7 \mathrm{~kg} \\
(\varnothing 19.0 \mathrm{~cm})\end{array}$ \\
\hline $45 w+\%$ & $\begin{array}{c}184.7 \mathrm{~kg} \\
(\varnothing 26.5 \mathrm{~cm})\end{array}$ & $\begin{array}{c}80.5 \mathrm{~kg} \\
(\varnothing 20.1 \mathrm{~cm})\end{array}$ & $\begin{array}{c}49.6 \mathrm{~kg} \\
(\varnothing 17.1 \mathrm{~cm})\end{array}$ & $\begin{array}{c}35.6 \mathrm{~kg} \\
(\varnothing 15.3 \mathrm{~cm})\end{array}$ \\
\hline $70 w+\%$ & $\begin{array}{c}87.2 \mathrm{~kg} \\
(\varnothing 20.6 \mathrm{~cm})\end{array}$ & $\begin{array}{c}36.5 \mathrm{~kg} \\
(\varnothing 15.4 \mathrm{~cm})\end{array}$ & $\begin{array}{c}23.7 \mathrm{~kg} \\
(\varnothing 13.4 \mathrm{~cm})\end{array}$ & $\begin{array}{c}18.2 \mathrm{~kg} \\
(\varnothing 12.2 \mathrm{~cm})\end{array}$ \\
\hline $93 w+\%$ & $\begin{array}{c}53.3 \mathrm{~kg} \\
(\varnothing 17.5 \mathrm{~cm})\end{array}$ & $\begin{array}{c}22.3 \mathrm{~kg} \\
(\varnothing 13.1 \mathrm{~cm})\end{array}$ & $\begin{array}{c}14.9 \mathrm{~kg} \\
(\varnothing 11.4 \mathrm{~cm})\end{array}$ & $\begin{array}{c}11.7 \mathrm{~kg} \\
(\varnothing 10.6 \mathrm{~cm})\end{array}$ \\
\hline Reactor-grade plutonium & $\begin{array}{c}14.6 \mathrm{~kg} \\
(\varnothing 11.4 \mathrm{~cm})\end{array}$ & $\begin{array}{c}6.92 \mathrm{~kg} \\
(\varnothing 8.86 \mathrm{~cm})\end{array}$ & $\begin{array}{c}5.29 \mathrm{~kg} \\
(\varnothing 8.10 \mathrm{~cm})\end{array}$ & $\begin{array}{c}4.58 \mathrm{~kg} \\
(\varnothing 7.72 \mathrm{~cm})\end{array}$ \\
\hline Fuel-grade plutonium & $\begin{array}{c}13.2 \mathrm{~kg} \\
(\varnothing 11.0 \mathrm{~cm} \text { ) }\end{array}$ & $\begin{array}{c}6.24 \mathrm{~kg} \\
(\varnothing 8.56 \mathrm{~cm})\end{array}$ & $\begin{array}{c}4.76 \mathrm{~kg} \\
(\varnothing 7.82 \mathrm{~cm})\end{array}$ & $\begin{array}{c}4.10 \mathrm{~kg} \\
(\varnothing 7.44 \mathrm{~cm})\end{array}$ \\
\hline Weapon-grade plutonium & $\begin{array}{c}11.5 \mathrm{~kg} \\
(\varnothing 10.5 \mathrm{~cm}) \\
\end{array}$ & $\begin{array}{c}5.53 \mathrm{~kg} \\
(\varnothing 8.22 \mathrm{~cm})\end{array}$ & $\begin{array}{c}4.26 \mathrm{~kg} \\
(\varnothing 7.54 \mathrm{~cm})\end{array}$ & $\begin{array}{c}3.71 \mathrm{~kg} \\
(\varnothing 7.20 \mathrm{~cm})\end{array}$ \\
\hline
\end{tabular}

and greatly reduces the absolute values compared to the corresponding unreflected critical masses. A more comprehensive set of data is listed in Table 1, where critical mass values of uranium for several enrichment levels and reflector thicknesses are listed. For reference purposes, data for typical plutonium compositions are also included.

The critical mass of uranium increases sharply with decreasing enrichment, which is relevant to the weapon-usability of uranium for a variety of reasons. Most importantly, a low critical mass simplifies the assembly of the final supercritical configuration, a process that requires swift acceleration of the previously subcritical components. ${ }^{10}$ The isotopic composition and the respective critical mass simultaneously affect other properties that are relevant to a material's weapon-usability. One of these aspects, the total neutron emission rate, is discussed below.

\section{Neutron Emission Rate}

The neutron emission rate in uranium and plutonium is mainly caused by spontaneous fission events. ${ }^{11}$ There are at least two basic assembly techniques for a nuclear weapon (gun-type and implosion) and both require a 
Table 2: Properties of the most important uranium and plutonium isotopes. ${ }^{13}$ Isotopic power includes contributions from $\alpha-, \beta-$, and $\gamma$-decay.

\begin{tabular}{lcccc}
\hline Nuclide & Half-life & Specific activity & Isotopic power & Spont. fission rate \\
\hline $\mathrm{U}-234$ & $2.46 \mathrm{E}+05 \mathrm{y}$ & $2.30 \mathrm{E}+08 \mathrm{~Bq} / \mathrm{g}$ & $1.79 \mathrm{E}-04 \mathrm{~W} / \mathrm{g}$ & $3.98 \mathrm{E}-03 \mathrm{l} /(\mathrm{g} \mathrm{s})$ \\
$\mathrm{U}-235$ & $7.04 \mathrm{E}+08 \mathrm{y}$ & $8.00 \mathrm{E}+04 \mathrm{~Bq} / \mathrm{g}$ & $5.99 \mathrm{E}-08 \mathrm{~W} / \mathrm{g}$ & $5.60 \mathrm{E}-06 \mathrm{l} /(\mathrm{g} \mathrm{s})$ \\
$\mathrm{U}-236$ & $2.34 \mathrm{E}+07 \mathrm{y}$ & $2.39 \mathrm{E}+06 \mathrm{~Bq} / \mathrm{g}$ & $1.75 \mathrm{E}-06 \mathrm{~W} / \mathrm{g}$ & $2.30 \mathrm{E}-03 \mathrm{l} /(\mathrm{g} \mathrm{s})$ \\
$\mathrm{U}-238$ & $4.47 \mathrm{E}+09 \mathrm{y}$ & $1.24 \mathrm{E}+04 \mathrm{~Bq} / \mathrm{g}$ & $8.50 \mathrm{E}-09 \mathrm{~W} / \mathrm{g}$ & $6.78 \mathrm{E}-03 \mathrm{l} /(\mathrm{g} \mathrm{s})$ \\
$\mathrm{Pu}-238$ & $8.78 \mathrm{E}+01 \mathrm{y}$ & $6.34 \mathrm{E}+11 \mathrm{~Bq} / \mathrm{g}$ & $5.67 \mathrm{E}-01 \mathrm{~W} / \mathrm{g}$ & $1.20 \mathrm{E}+03 \mathrm{l} /(\mathrm{g} \mathrm{s})$ \\
$\mathrm{Pu}-239$ & $2.41 \mathrm{E}+04 \mathrm{y}$ & $2.30 \mathrm{E}+09 \mathrm{~Bq} / \mathrm{g}$ & $1.93 \mathrm{E}-03 \mathrm{~W} / \mathrm{g}$ & $7.11 \mathrm{E}-03 \mathrm{l} /(\mathrm{g} \mathrm{s})$ \\
$\mathrm{Pu}-240$ & $6.57 \mathrm{E}+03 \mathrm{y}$ & $8.39 \mathrm{E}+09 \mathrm{~Bq} / \mathrm{g}$ & $7.06 \mathrm{E}-03 \mathrm{~W} / \mathrm{g}$ & $4.78 \mathrm{E}+02 \mathrm{l} /(\mathrm{g} \mathrm{s})$ \\
$\mathrm{Pu}-241$ & $1.44 \mathrm{E}+01 \mathrm{y}$ & $3.82 \mathrm{E}+12 \mathrm{~Bq} / \mathrm{g}$ & $3.28 \mathrm{E}-03 \mathrm{~W} / \mathrm{g}$ & $9.18 \mathrm{E}-04 \mathrm{l} /(\mathrm{g} \mathrm{s})$ \\
$\mathrm{Pu}-242$ & $3.74 \mathrm{E}+05 \mathrm{y}$ & $1.46 \mathrm{E}+08 \mathrm{Bg} / \mathrm{g}$ & $1.17 \mathrm{E}-04 \mathrm{~W} / \mathrm{g}$ & $8.04 \mathrm{E}+02 \mathrm{l} /(\mathrm{g} \mathrm{s})$ \\
\hline
\end{tabular}

characteristic assembly-time to reach the final supercritical configuration of the weapon. These assembly-times are on the order of $1 \mathrm{~ms}$ for gun-type and $1 \mu \mathrm{s}$ for implosion, respectively. ${ }^{12} \mathrm{~A}$ spontaneous fission event during the assembly process may lead to a premature initiation of the neutron chain reaction and ultimately cause a so-called 'fizzle' of the device. Table 2 lists the reference emission rates for the main uranium and plutonium isotopes. ${ }^{13}$

During the development of the first nuclear weapons within the U.S. Manhattan Project, it became apparent that plutonium could not be used in the simple gun-type method, in which a subcritical projectile of fissile material is propelled towards a fissile target. Due to its low spontaneous fission rate, only highly enriched uranium is an obvious candidate for this assembly technique. As can be inferred from Table 2, even pure Pu-239 requires an assembly speed that is higher by three orders of magnitude than is required for U-235. Assembly-times of close to $1 \mu \mathrm{s}$ can only be achieved using special highexplosives with an implosion-type design, in which a sphere or spherical shell of material is symmetrically imploded and compressed beyond the normal density of the metal.

For reduced uranium enrichment levels, neutron emission rates increase due to the higher fractional and absolute content of uranium-238. At the same time, total neutron emission goes up with an increased assembly-time, which is likely to result from the larger amount of nuclear material in the device. ${ }^{14}$ Eventually, a simple gun-type assembly of a uranium-device might become difficult or even impossible, assuming that the proliferator is not very experienced in the design of nuclear weapons. ${ }^{15}$

The probability that $k$ events occur in a given time interval $\Delta t$ for a stochastic process characterized by a decay constant $\lambda$ is described by the Poisson distribution. In the present context, one is interested in $k=0$, i.e., in the probability that no spontaneous fission event occurs in $\Delta t$.

$$
p(\lambda, k, \Delta t)=\left[\frac{(\lambda \Delta t)^{k}}{k !} \exp (-\lambda \Delta t)\right], \quad \text { or } \quad p(\lambda, 0, \Delta t)=\exp (-\lambda \Delta t) .
$$




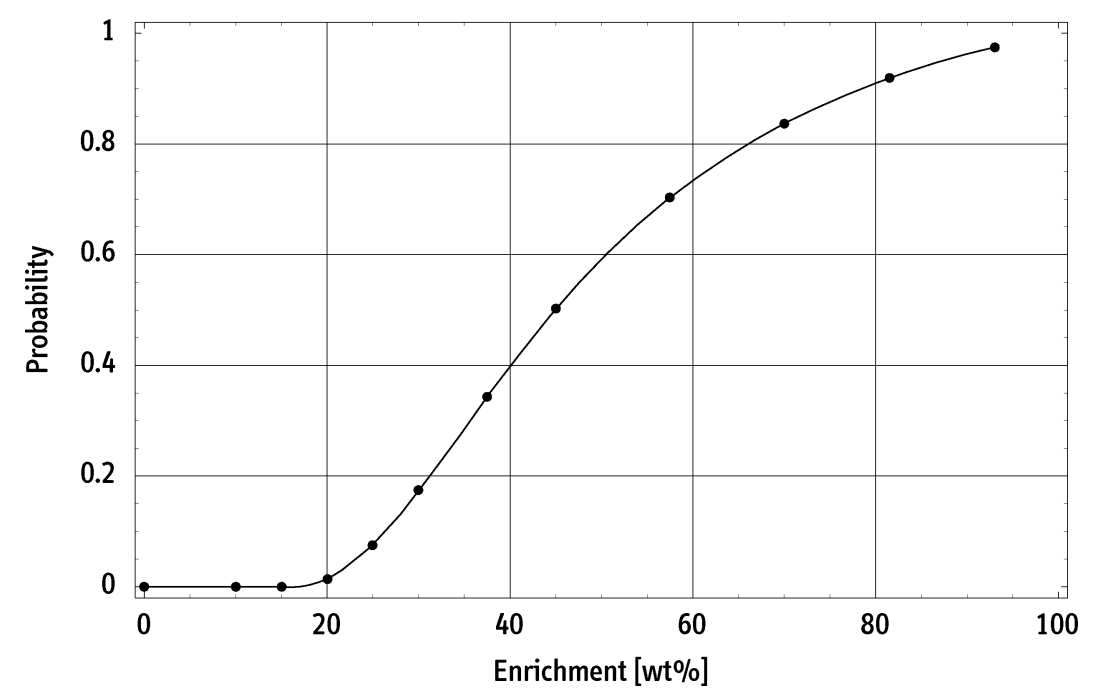

Figure 2: Probability of a spontaneous-fission-free millisecond in one bare critical mass of uranium of the given enrichment. Numerical values are 1.4\% (LEU at 19.75\%), 50.2\% (HEU at $45 \%$ ), and $97.5 \%$ (WGU at $93 \%$ ).

The decay constant $\lambda$ is given by the specific spontaneous fission rate as listed in Table 2 multiplied by the corresponding mass of the material. The amount of uranium required for a simple gun-type device is on the order of one bare critical mass and corresponding values are taken from Table 1. Given these assumptions, Figure 2 shows the probability that no spontaneous fission event occurs in $1 \mathrm{~ms}$ as a function of uranium enrichment. The figure clearly illustrates that the chances for a spontaneous-fission-free millisecond are very high (about $97.5 \%$ ) for weapon-grade uranium; but also that the chances are extremely low if low-enriched uranium is used instead (about 1.4\%), even if one assumes that the assembly-time does not increase when LEU is used in the device.

Note also that the characteristics of uranium recovered from irradiated HEU-fuel are very similar to fresh WGU if strong neutron emitters, namely some plutonium and curium isotopes, can be successfully removed during reprocessing. ${ }^{16}$ For HEU-fuel at $40 \%$ U-235 burnup, characterized by a residual enrichment of $81.0 \%$, the overall probability of a neutron-free millisecond is still $94.5 \% .{ }^{17}$ In consequence, and recalling also that the uranium used in the Hiroshima bomb was reportedly enriched to $80 \%$ on average, irradiated HEU-fuel would clearly be usable in a simple gun-type device.

So far, only static or initial properties of the material and the configuration have been discussed. Additional characteristics of the fissile material determine the dynamics of the explosive process. As an example, the characteristic time constant $\alpha(t)$ can be defined for a given material and configuration. 
$\alpha(t)$ determines the evolution of the neutron population $n(t)$ in the fissile material and, hence, the time-scale of the fission chain reaction.

$$
n(t)=n_{0} \exp (\alpha(t) t) \quad \text { with } \quad \alpha(t)=\frac{k_{\text {eff }}(t)-1}{\tau_{\text {rem }}(t)} .
$$

Here, $k_{\text {eff }}$ is the effective multiplication factor of the device and $\tau_{\text {rem }}$ the removal lifetime for neutrons controlled by absorption and leakage. The neutron population grows exponentially as long as $\alpha>0$. Approximating the time-dependency of $\alpha$, once the expansion of the nuclear device during the explosion has begun, is far beyond the scope of this article. Even a simple look at the initial $\alpha=\alpha_{0}$, however, reveals further significant differences in the properties of enriched uranium compositions (Figure 3). Again, the decreasing value of $\alpha$ with lower enrichment degrades the weapon-usability of the material. The chain-reaction proceeds more slowly, which ultimately reduces the total number of completed neutron generations before the expanding device becomes subcritical. The initial value of $\alpha$ has been used elsewhere as the key variable to estimate the yield of a nuclear device. ${ }^{18}$

The preceding discussion demonstrates that there are important qualitative differences between HEU and LEU other than the critical mass. The neutron emission rate is particularly relevant if one is concerned about the feasibility of crude nuclear weapons or explosive devices based on the gun-type design, or even of so-called improvised nuclear devices (INDs). LEU is clearly

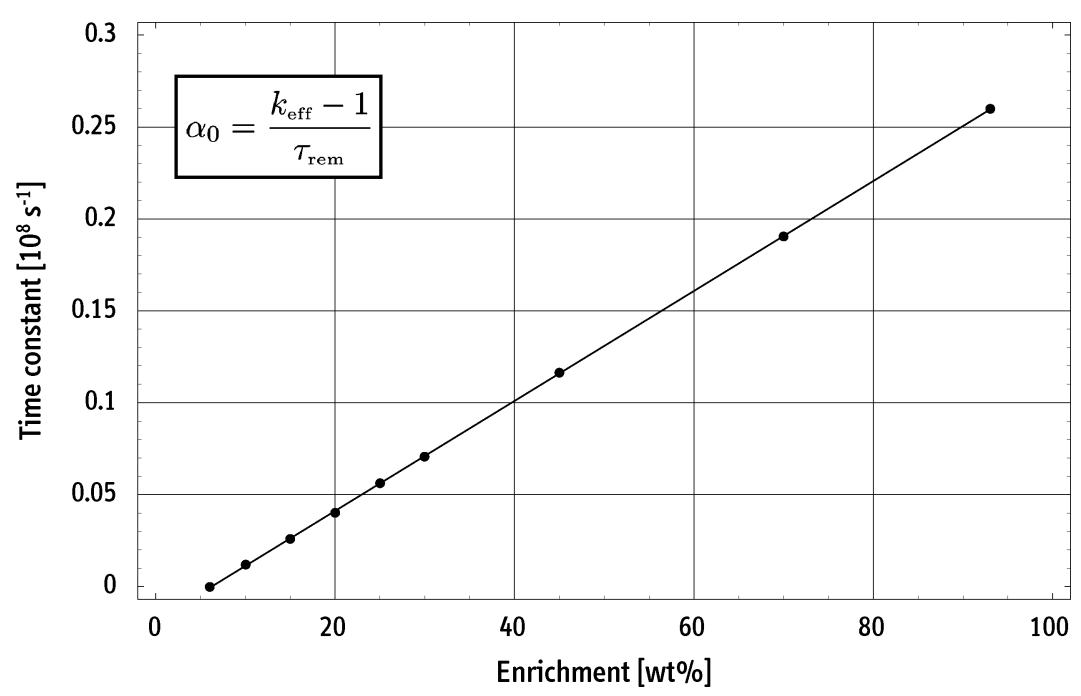

Figure 3: Characteristic time constant $\alpha$ for a supercritical uranium configuration of two bare critical masses at the standard density of $19.0 \mathrm{~g} / \mathrm{cc}$. For enrichment levels of $6 \%$ and below no bare critical mass of uranium exists. Data obtained in MCNP 4C calculations at $300 \mathrm{~K}$. 
not suitable for these scenarios as one can directly infer from the neutron emission rates combined with the slow assembly process. Very high enrichment levels are clearly favorable and it is plausible to assume that a proliferator with access to an advanced nuclear infrastructure will undertake every effort to enrich available uranium stocks to weapon-grade, i.e., to $90 \%$ and beyond.

In the following analysis, uranium compositions of various enrichment levels have to be compared to each other in order to quantify the net proliferation potential of different research reactor fuels. To this end, usability factors $\eta$ are introduced in order to account for the reduced "quality" of uranium with reduced enrichment levels. Two simple candidate factors emerge from the preceding discussion: the probability of a neutron-free millisecond, which is relevant to the feasibility of gun-type devices, and the time constant $\alpha_{0}$ for a more general estimate of a material's weapon-usability applying to both gun-type and implosion-type designs (Figures 2 and 3, respectively).

\section{EFFECTIVE STRATEGIC VALUE OF NUCLEAR MATERIAL}

In order to get representative and reasonably accurate estimates of the spent fuel compositions required for the proliferation assessment below, extensive cell burnup calculations have been performed for a typical MTR-type reactor geometry and various initial uranium enrichments. Results are scaled to a facility operated at a thermal power level of $30 \mathrm{MW}$ and were obtained using a computational system, which has been developed specifically for research reactor analysis. The system is primarily based on the existing neutronics codes MCNP 4C and ORIGEN 2.2. ${ }^{19}$ Table 3 summarizes the basic assumptions and input data used in the calculations, assuming an infinite array of MTR-type fuel plates.

A variety of different fuel enrichments are studied, ranging from $93 \%$ down to $5 \%$. Below that limit, operation of a typical MTR-type geometry is unrealistic. The concentration of uranium-235 is held constant for all enrichment levels by increasing the total uranium density in the fuel matrix correspondingly. With the uranium-235 density fixed, the various fuels can be considered equivalent, although, in practice, one would have to increase the effective uranium-235 density for a fixed core geometry somewhat to maintain similar performance or cycle length of the reactor. The selected value of $0.948 \mathrm{~g}(\mathrm{U}-235) / \mathrm{cc}$ corresponds

Table 3: Input data and assumptions for cell burnup calculations.

Meat thickness

Cladding thickness

Coolant channel

Fixed uranium-235 density

Average power density in core

Thermal power of reactor
$0.60 \mathrm{~mm}$

$0.38 \mathrm{~mm}$

$2.20 \mathrm{~mm}$

$0.948 \mathrm{~g} / \mathrm{cc}$

$125 \mathrm{~kW} / \mathrm{l}$

$30 \mathrm{MW}$ 


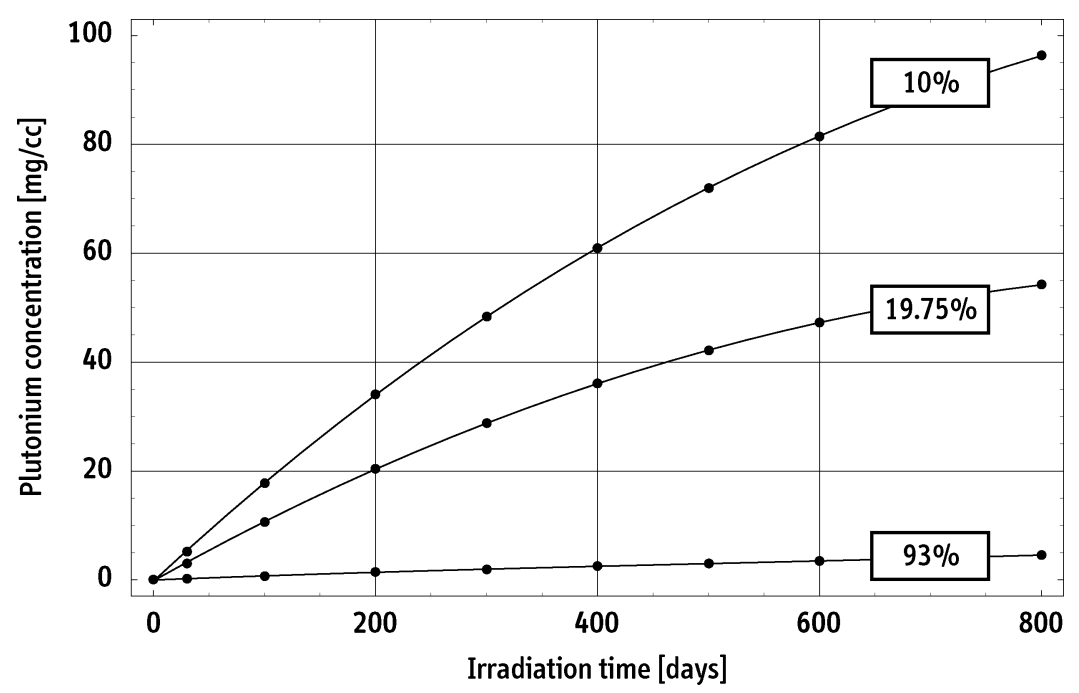

Figure 4: Specific plutonium production in MTR-type fuel for various enrichment levels. See Table 4 to correlate irradiation time with uranium-235 burnup. Results based on cell burnup calculations.

to today's standard value of $4.8 \mathrm{~g}(\mathrm{U}) / \mathrm{cc}$ at an enrichment of $19.75 \%$. For HEUfuel the total density is close to $1.0 \mathrm{~g}(\mathrm{U}) / \mathrm{cc}$, which represents a typical fuel density used until the late 1970s when development of high-density LEU-fuels began.

The burnup calculations yield the time-dependent concentrations of several hundred isotopes generated in the fuel. As an example of these results, Figure 4 shows the specific plutonium buildup for selected enrichment levels. Scaled to a $30 \mathrm{MW}$ reactor, Table 4 summarizes the most important numerical results obtained in these calculations for U-235 target burnups of $20 \%, 40 \%$, and $60 \% .{ }^{20}$

The main difficulty in assessing the proliferation potential or the "strategic value" of the fissile inventory associated with reactor operation is to relate and compare the corresponding uranium and plutonium inventories in the fuel. Uranium may be separated from the fresh fuel and possibly further enriched. In addition, both plutonium and uranium may be separated from the irradiated fuel. The feasibility of these approaches depends upon the skills of the proliferator and upon the availability of the required nuclear infrastructure. The following analysis is therefore highly simplified in making inevitable adhoc assumptions in that respect.

Several assessment options are suggested. They are based on the fundamental assumption that a one-year's supply of fresh (unirradiated) fuel required to operate the reference reactor and a one-year's amount of spent fuel at $40 \% \mathrm{U}-235$ burnup are available. Different assumptions are made, however, regarding the ultimate usage of the material in a nuclear device depending upon the nuclear capability of the proliferator. 


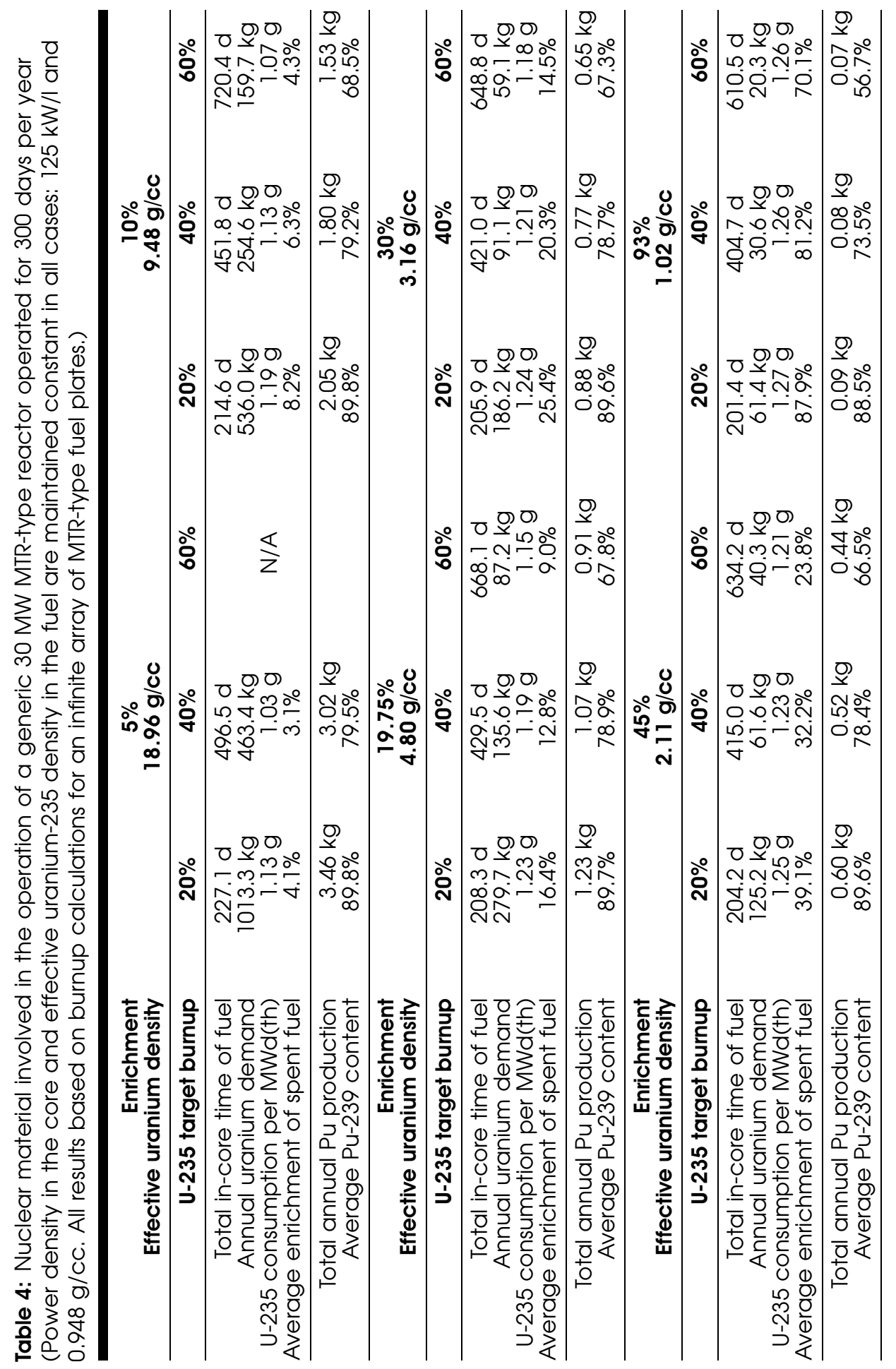




\section{Basic Nuclear Capability}

For the first scenario, it is assumed that an effort is undertaken to build a crude nuclear device based on the gun-type method. Only uranium is usable in such a device and, while the uranium is recovered from the spent fuel, the respective plutonium inventory is discarded from further use. ${ }^{21}$ The reference quantity of fissile material used for this assessment is one bare critical mass of uranium $M_{B}$, which is about the quantity needed for a gun-type device. As indicated previously, the diminished usability of material with reduced U-235content is taken into account by applying a weighting factor $\eta$ to the material. The relative probability for a spontaneous-fission-free millisecond $\eta_{1}=p / p_{\mathrm{HEU}}$ in the material is used for this purpose (Figure 2). The total strategic value $\mathrm{CM}_{\mathrm{A}}^{*}$ of the material extracted from the fuel is defined as follows.

$$
\mathrm{CM}_{\mathrm{A}}^{*}=\eta_{1}\left(\epsilon_{\mathrm{FF}}\right) \frac{m_{\mathrm{FF}}}{M_{B}\left(\epsilon_{\mathrm{FF}}\right)}+\eta_{1}\left(\epsilon_{\mathrm{SF}}\right) \frac{m_{\mathrm{SF}}}{M_{B}\left(\epsilon_{\mathrm{SF}}\right)} .
$$

The indices FF and SF of mass $m$ and enrichment level $\epsilon$ refer to the uranium contained in the fresh and the spent fuel, respectively. Based on the results obtained in the burnup calculations summarized in Table $4, \mathrm{CM}_{\mathrm{A}}^{*}$-values are calculated for a target burnup of $40 \% \mathrm{U}-235$ and a variety of enrichment levels. Results are shown in Figure 5. Table 5 lists numerical data on fissile inventories, critical masses, and weighting factors.

With decreasing enrichment levels, the estimated strategic value of the fuel decreases for two reasons: both the critical mass ratio $m / M_{B}$ and the usability

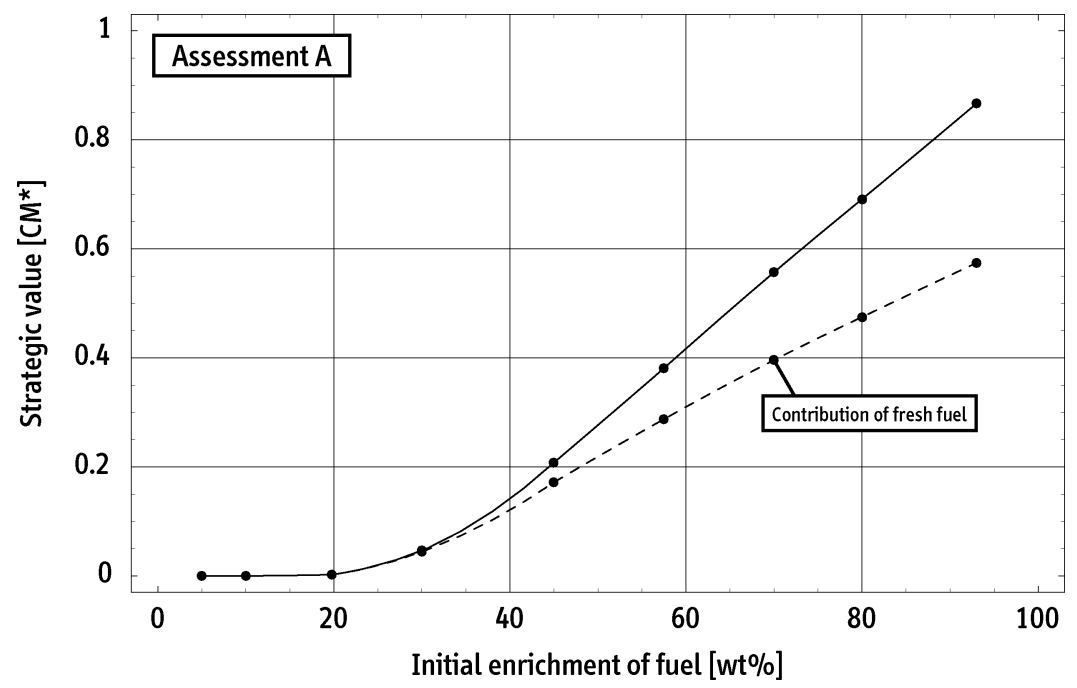

Figure 5: Basic nuclear capability. Strategic value of fissile materials associated with research reactor operation, assuming that only uranium is extracted and used from the fuel. Assumed objective is the construction of a crude gun-type device. The plutonium inventory in the spent fuel is discarded from further use. 


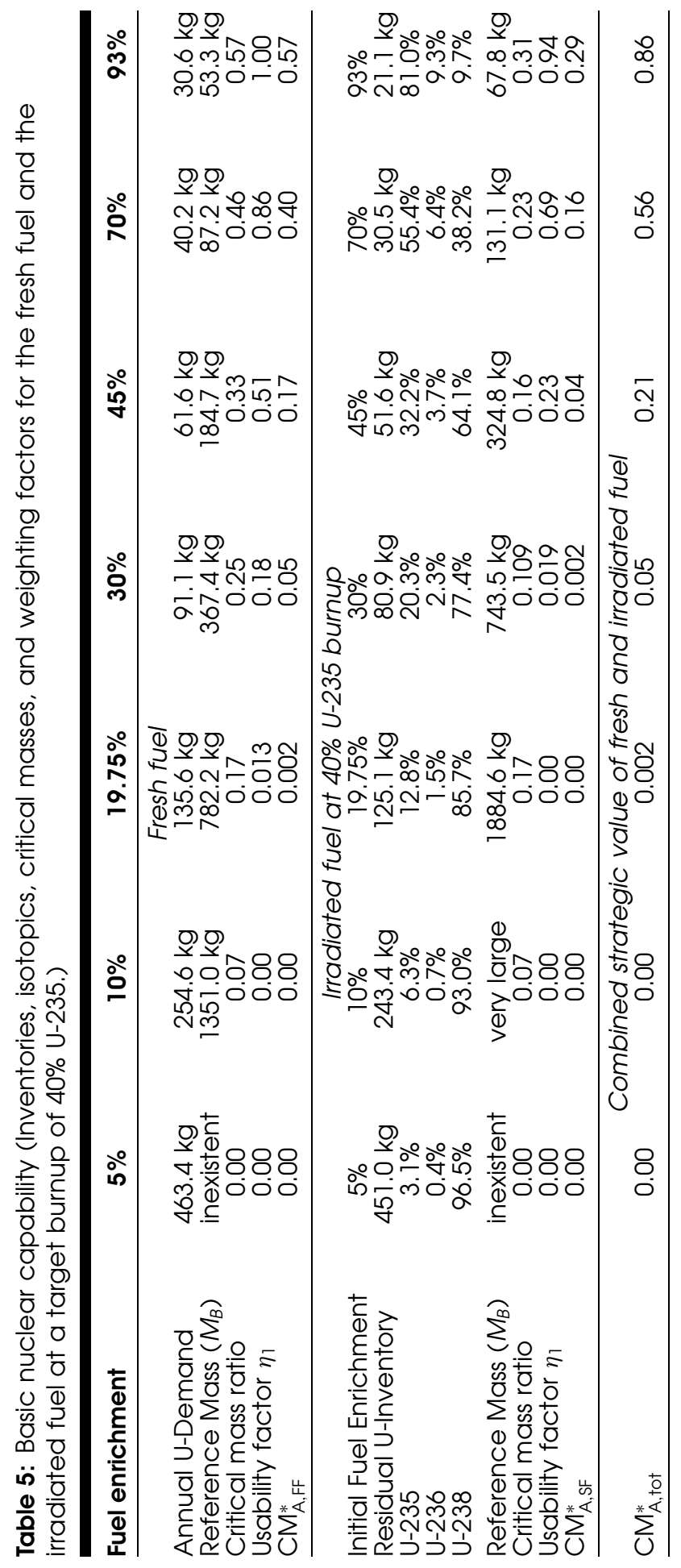


factor drop simultaneously to low values compared to the WGU-case. For the reference reactor, the material extracted from the fresh and irradiated fuel reaches a $\mathrm{CM}_{\mathrm{A}}^{*}$ of 0.86 if the facility is fueled with WGU. The absolute mass of recoverable uranium is thus close to the amount needed for a crude gun-type device. About one-third of the total value is associated with the uranium contained in the irradiated fuel. At $45 \%$ enrichment, $\mathrm{CM}_{\mathrm{A}}^{*}$ has dropped to 0.21 , and it essentially reaches zero for enrichment levels of $20 \%$ and below. As expected, because the plutonium contained in the spent fuel is discarded in this scenario, lowest enrichment levels minimize the proliferation potential of the fuel.

\section{Advanced Nuclear Capability}

The fundamental assumption of the advanced scenario is that both uranium and plutonium are extracted and used for weapons purposes. This strategy would therefore require a successful implementation of the more sophisticated implosion-type design. As a corollary, however, much less material is needed to build the device. The reference quantities used in the following are critical masses of uranium and plutonium enclosed by a thick $(15 \mathrm{~cm})$ beryllium reflector. Values are taken from Table 1.

Two variants of the advanced scenario (B1 and B2) are considered. As in the low-tech scenario, in the main scenario B1, no attempt is made to enrich such material to weapon-grade, i.e., to $93 \%$. Similarly, the usability of uranium is corrected using a weighting factor, but instead of the spontaneus-fission rate, ${ }^{22}$ the time constant $\alpha_{0}$ is used to characterize the material's weapon-usability. The weighting factor is defined by $\eta_{2}=\alpha / \alpha_{\mathrm{HEU}}$. While the reflected critical masses of uranium $\left(M_{R}\right)$ strongly depend upon the enrichment of the material, the critical mass values of plutonium are virtually identical $(4.0 \mathrm{~kg})$ for all compositions encountered in research reactor fuel of the specified burnup (see Table 6). The total strategic value of the fissile material for Assessment B1 is given by:

$$
\mathrm{CM}_{\mathrm{B} 1}^{*}=\eta_{2}\left(\epsilon_{\mathrm{FF}}\right) \frac{m_{\mathrm{FF}}}{M_{R}\left(\epsilon_{\mathrm{FF}}\right)}+\eta_{2}\left(\epsilon_{\mathrm{SF}}\right) \frac{m_{\mathrm{SF}}}{M_{R}\left(\epsilon_{\mathrm{SF}}\right)}+\frac{m_{\mathrm{Pu}}}{4.0 \mathrm{~kg}}
$$

The results for Assessment B1 are illustrated in Figure 6 and summarized in Table 6. Compared to the low-tech scenario, in which the construction of a gun-type weapon was assumed, the absolute strategic values are now much higher and reach a $\mathrm{CM}_{\mathrm{B} 1}^{*}$ of 3.90 for weapon-grade uranium. The value of $\mathrm{CM}_{\mathrm{B} 1}^{*}$ falls rapidly for sub-weapon-grade uranium, but plutonium production simultaneously becomes more important. As a result, a minimum value of $\mathrm{CM}_{\mathrm{B} 1}^{*}$ is now observed for an enrichment level of 15-20\%, below which plutonium starts to dominate the proliferation potential of the fuel. ${ }^{23}$ This result, of course, is consistent with the international efforts to convert research reactors to LEU just 


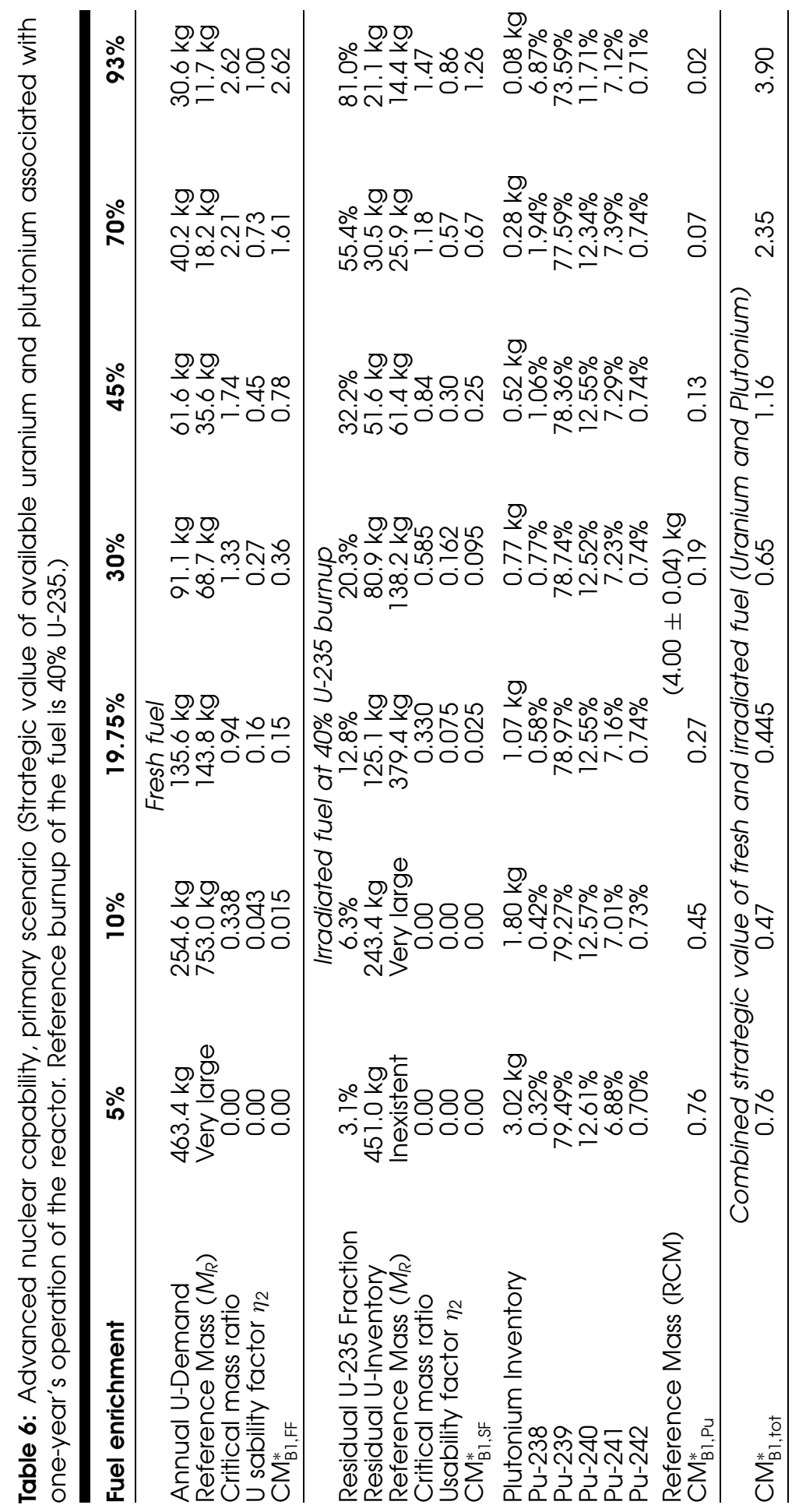




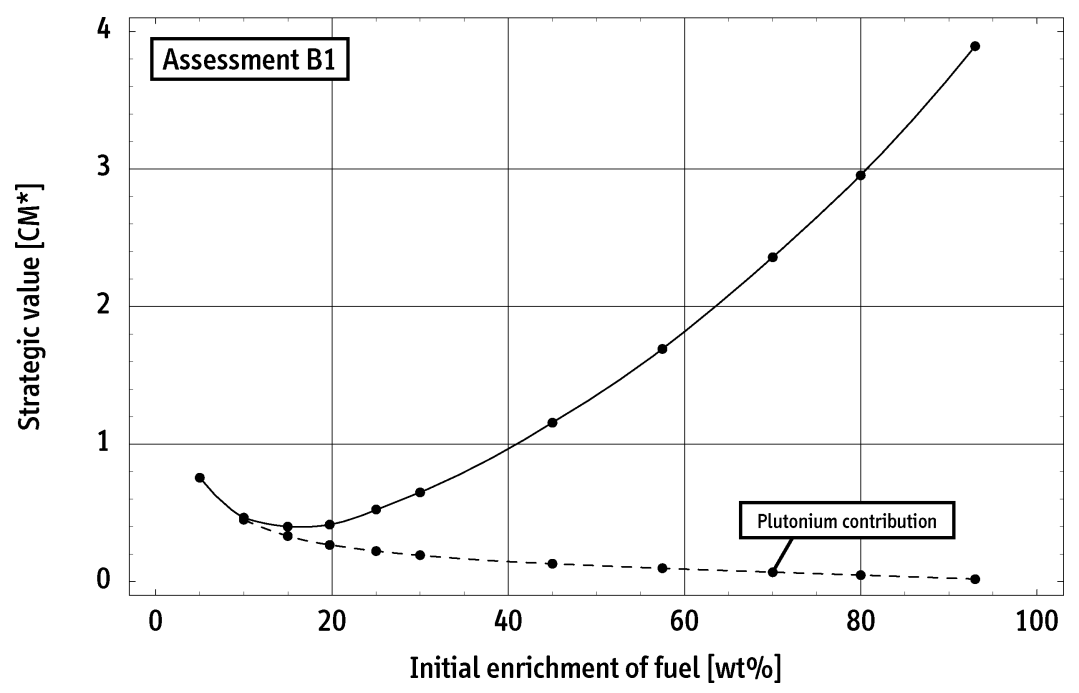

Figure 6: Advanced nuclear capability, primary scenario. Strategic value of fissile materials associated with research reactor operation assuming that uranium and plutonium are used for an implosion-type weapon. Dashed line indicates plutonium contribution to total value.

below $20 \%$ enrichment. Compared to WGU, the effective proliferation potential of the fuel is reduced by almost $90 \%$ for LEU at $19.75 \%$.

A secondary advanced-technology scenario B2 is based on the assumption that a limited amount of separative work, say from a laboratory or pilot-scale enrichment facility, is available to process diverted fuel. The objective would be to produce a maximum amount of weapon-grade uranium, i.e., HEU at $93 \%$, using the stock of preenriched uranium recovered from the fresh fuel and potentially also from the spent fuel. In the analysis that follows, values between 10 SWU and 640 SWU are considered. These values are extremely small compared to capacities generated by commercial enrichment plants. However, if much more enrichment capacity were available to the proliferator, there would be no need to divert the limited amount of (presumably safeguarded) research reactor fuel. Instead, undeclared feed-stock of natural uranium could be used to produce HEU directly. If one assumes, for example, that centrifuge technology is available to process the feed material, a set of 60 machines could be used to produce $10 \mathrm{SWU}$ in one month assuming that each centrifuge has an output of about $2 \mathrm{SWU} / \mathrm{yr}$, a typical value for a first generation machine. In the case of centrifuges, it is unreasonable to assume that a cascade with many fewer than 50-60 machines could be operated in a meaningful way. ${ }^{24} 10 \mathrm{SWU}$ per month therefore represent a practical lower limit.

In general, the proliferator has the choice to distribute the available enrichment capacity between the fresh and the spent fuel. Even though SWU's are generally more effectively used on the fresh fuel, under specific circumstances, it may be favorable to process the spent fuel, too. Obviously, if the fresh fuel 


\section{Glaser}

is already weapon-grade, then the entire enrichment capacity could be used to process the irradiated fuel. To keep the analysis as simple as possible, only three basic cases are considered below: the proliferator may either spend the available SWUs on the fresh fuel, expend them on the irradiated fuel, or distribute them equally between both. The amount of weapon-grade uranium that can be produced using the uranium feed-stock is determined with special expressions for multicomponent uranium enrichment, which are required to correctly account for the U-236 content in the irradiated fuel. ${ }^{25}$

$$
\begin{aligned}
S W U & =P V\left(x_{P}\right)+T V\left(x_{T}\right)-F V\left(x_{F}\right), \text { and } \\
0 & =P H\left(x_{P}\right)+T H\left(x_{T}\right)-F H\left(x_{F}\right) . \\
\text { where } F & =P+T, \\
x_{F} F & =x_{P} P+x_{T} T, \text { and } \\
y_{F} F & =y_{P} P+y_{T} T, \\
\text { with } V\left(x_{i}, y_{i}\right) & =\left(2 x_{i}-1+4 y_{i}\right) \ln \left[\frac{x_{i}}{1-x_{i}-y_{i}}\right], \quad \text { and } \\
H\left(x_{i}, y_{i}\right) & =y_{i} \sqrt[3]{\frac{1-x_{i}-y_{i}}{x_{i}}} .
\end{aligned}
$$

The indices $F, P$, and $T$ refer to the feed, the product, and the tails, while $x$ and $y$ denote the isotopic fraction of $\mathrm{U}-235$ and $\mathrm{U}-236$ in the respective streams.

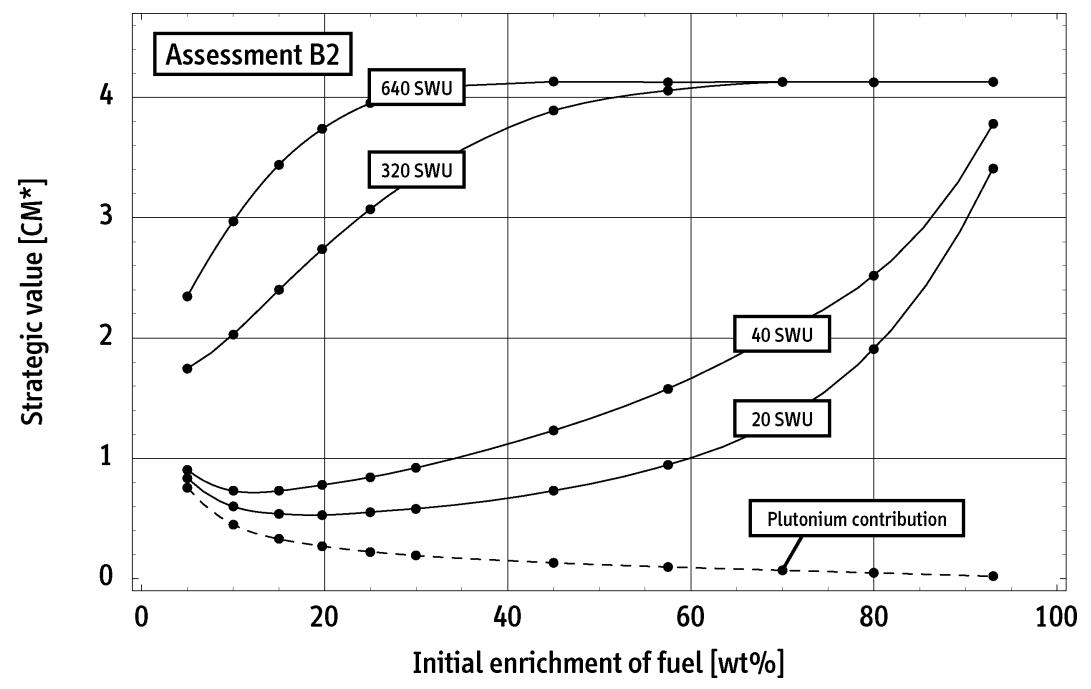

Figure 7: Advanced nuclear capability, secondary scenario. Strategic value assuming that a specified amount of separative work is available to produce weapon-grade uranium. Dashed line indicates plutonium contribution to total value. 


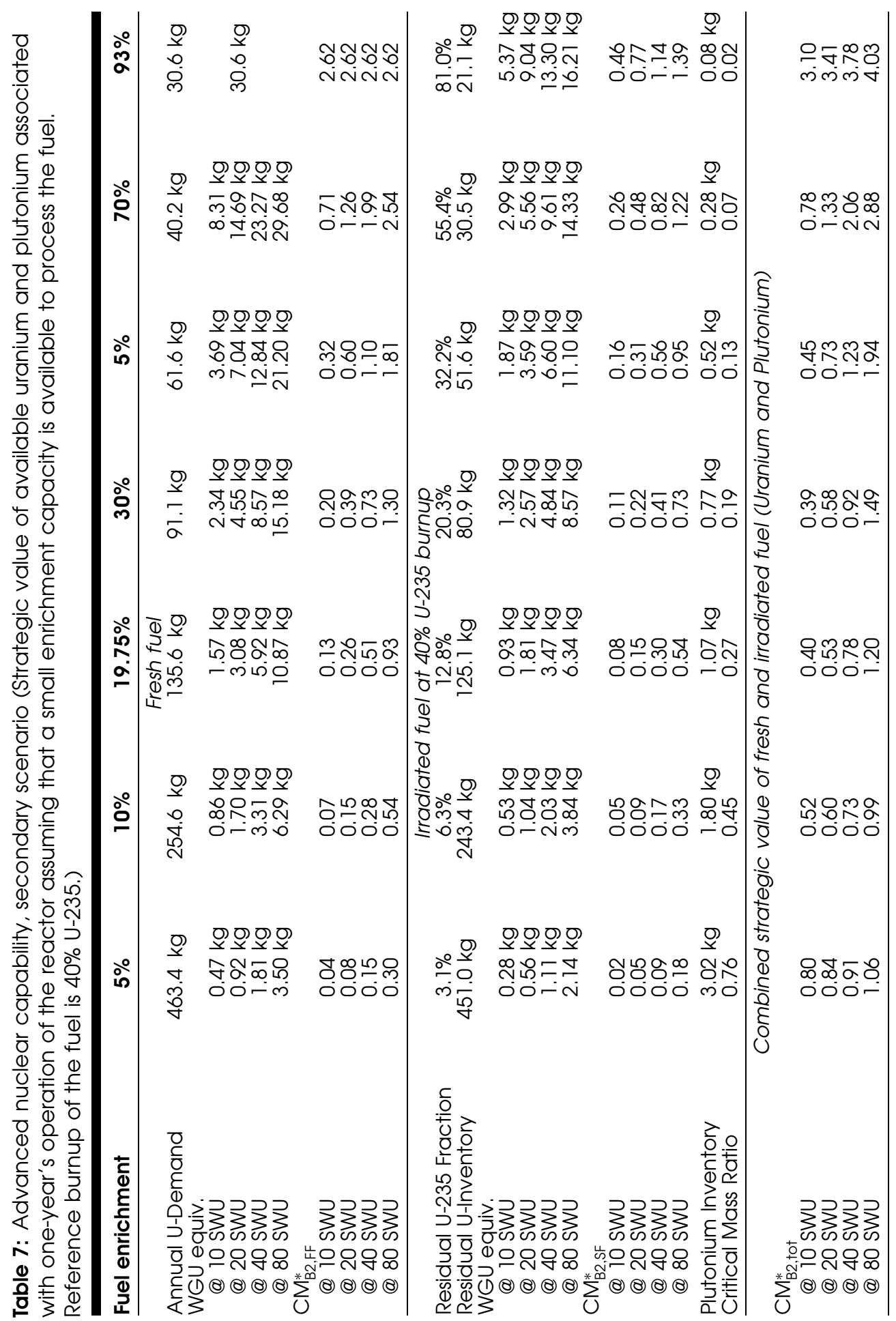




\section{Glaser}

As required, these expressions simplify to the standard equations for uranium enrichment if the third component (U-236) is not present in the feed-material. The initial fuel inventory $F$ with isotopic fractions $x_{F}$ and $y_{F}$ of uranium-235 and -236 , respectively, is processed with a given SWU capacity to produce the final product $P$ with $x_{P}=0.93$. All unknown variables, including the product mass $P$, are determined by the set of equations above, which can be solved numerically. Once the equivalent amount of the product WGU is known, the final estimate of the total strategic value is assigned via:

$$
\mathrm{CM}_{\mathrm{B} 2}^{*}=\frac{m_{\mathrm{WGU}, \mathrm{FF}}+m_{\mathrm{WGU}, \mathrm{SF}}}{11.7 \mathrm{~kg}}+\frac{m_{\mathrm{Pu}}}{4.0 \mathrm{~kg}} .
$$

Results for this scenario are illustrated in Figure 7 and numerical values listed in Table 7. Similar to Assessment B1, there is a minimum of $\mathrm{CM}_{\mathrm{B} 2}^{*}$ for low enrichment capacities (10-40 SWU). The position of this weakly pronounced minimum is close to an initial fuel enrichment level of $20 \%$, but shifts with increasing SWU-capacity to lower values. As anticipated, for high SWU-values, virtually the entire amount of U-235 can be extracted from the feed-material. For instance, 320 SWU are sufficient to collect more than $90 \%$ of the maximum $\mathrm{CM}_{\mathrm{B} 2}^{*}$ for initial fuel enrichment levels of as low as 40\%. For $640 \mathrm{SWU}$, this fraction is obtained for all enrichment levels beyond 20\% (see Figure 7). In these cases, the distinction between LEU and HEU obviously is no longer relevant.

The results of both advanced assessments (B1 and B2) demonstrate that an enrichment level close to $20 \%$ does indeed minimize the strategic value of the fissile material involved in operation of a given MTR-type reactor. For enrichment levels of $15 \%$ and below, the plutonium component dominates proliferation concerns associated with research reactor fuel. ${ }^{26}$ For intermediate enrichments above $20 \%$, the proliferation potential of the nuclear material strongly depends on the assessment type, i.e., on the assumptions made regarding the proliferator's capabilities and available infrastructure. Nevertheless, the absolute values increase in all scenarios above $20 \%$ enrichment. As expected, the use of weapon-grade uranium to fuel a research reactor clearly maximizes the overall proliferation potential associated with reactor operation.

\section{CONCLUSION}

The quantitative analysis presented above clearly demonstrates the usefulness of the distinction between LEU and HEU. Uranium fuel below $20 \%$ virtually eliminates the possibility that the material could be directly used for the construction of a nuclear explosive device. Specifically, as some straightforward considerations show, LEU cannot be used in a simple gun-type device, both because of its large critical mass and the corresponding neutron emission rate. Simultaneously and coincidentally, at an enrichment level between 15-20\%, 
plutonium production is sufficiently suppressed to minimize the total strategic value of the material if implosion-type technology is available. For both reasons, the $20 \%$ limit represents a reasonable and even optimum choice as a conversion goal for research reactors.

The analysis therefore challenges the tendency of some recent research reactor projects, in which fuel enrichments beyond the $20 \%$ limit are considered again. Most prominently, the new German research reactor FRM-II, which became operational in 2004 and is currently using 93\%-enriched fuel, is required to be converted to an enrichment not exceeding $50 \%$ by December $2010 .{ }^{27}$ Even though this enrichment reduction is laudable, current plans of the operator do contemplate an enrichment of exactly $50 \%$ for the converted reactor. ${ }^{28}$ Similarly, designers of the French Jules Horowitz Reactor (JHR), which was initially planned for low-enriched fuel, currently consider the use of 30-35\%-enriched uranium as a fall-back option. More recent developments suggest that this option will indeed be exercised. ${ }^{29}$ In summary, after a two-decade period of close compliance with the LEU design-goal, there is an emerging attitude among designers, operators, and licensing authorities to interpret the conversion goal for research reactors as something other than a sharp constraint. Based on the data and the analysis presented above, this trend cannot be justified by technical arguments as it clearly reduces the proliferation resistance of the nuclear fuel cycle.

\section{APPENDIX}

\section{DEDICATED PLUTONIUM PRODUCTION IN MTR-TYPE REACTORS}

Complementary to an assessment of the strategic value of the nuclear material associated with regular operation of a facility, the effectiveness of a dedicated plutonium production campaign is briefly discussed for reference purposes.

A plutonium production campaign can take place either in a specially-built military production reactor or in a research or power reactor that was not initially designed for plutonium production. In the case of the research reactor, plutonium production can be carried out covertly or overtly, that is, an attempt can or cannot be made to conceal this mode of operation from outsiders. ${ }^{30}$ Plutonium production in an MTR-type reactor can be optimized if the core is loaded with so-called driver fuel elements to maintain the reactor critical and target fuel elements to generate the plutonium product. The driver fuel may be highly enriched, while the target material may contain either natural or depleted uranium. ${ }^{31}$

The development and analysis of detailed production scenarios is beyond the scope of this study, but a rough estimate is possible based on the neutron balance in a typical MTR-type reactor alone. The fission and neutron release 
rate per $\mathrm{MW}$ (th) can be specified using typical values for the energy and neutron release per fission event of $200 \mathrm{MeV}$ and $v=2.4$, respectively.

$1 \mathrm{MW}(\mathrm{th})$ is equivalent to $3.12 \times 10^{16} \mathrm{fi} / \mathrm{s}$ or $7.50 \times 10^{16} \mathrm{n} / \mathrm{s}$.

Typically 25-35\% of all neutrons released in an MTR-type reactor are not required to maintain criticality of the reactor and are therefore available for other purposes. Assuming that all those neutrons are absorbed in the target material and indeed lead to plutonium buildup, a theoretical upper limit of total plutonium production can be specified.

$$
\xi(\max ) \approx 0.65-0.90 \mathrm{~g}(\mathrm{Pu}) / \mathrm{MWd}(\mathrm{th}) .
$$

In practice, a production rate close to $\xi(\max )$, which would be equivalent to a net conversion ratio of $0.55-0.80,{ }^{32}$ is not achievable. Due to the relatively compact core design of typical MTR-type reactors, a significant fraction of the neutrons can be expected to leak from the core. In addition, parasitic neutron absorption in structural and other materials, as well as in the plutonium itself, will further reduce the efficiency. ${ }^{33}$ In making the ad hoc assumption that these effects decrease efficiency by an additional 30-40\%, a practical plutonium production rate $\xi$ (eff) can be estimated.

$$
\xi(\text { eff }) \approx 0.4-0.6 \mathrm{~g}(\mathrm{Pu}) / \mathrm{MWd}(\mathrm{th})
$$

Based on these values and scaled to the previously discussed generic $30 \mathrm{MW}$ reactor operated 300 days per year, the maximum plutonium production rate achievable in a dedicated plutonium production campaign is $3.6-5.4 \mathrm{~kg}(\mathrm{Pu}) / \mathrm{yr}$.

Quite consistently, more detailed analyses of production scenarios conclude that $3-6 \mathrm{~kg}$ of plutonium can be produced annually in a generic MTR-type reactor rated at $30 \mathrm{MW}{ }^{34}$ These numbers can be compared to the regular and inevitable plutonium buildup in a $30 \mathrm{MW}$ LEU-fueled reactor $(19.75 \%)$, which is on the order of $1 \mathrm{~kg}(\mathrm{Pu}) / \mathrm{yr}$ (see Table 4). Note also that plutonium production in a fictitious MTR-type reactor fueled with slightly enriched uranium (5\%) and operated at relatively low burnup of the fuel (20\%) is already close to the production rate achieved in dedicated campaigns in MTR-type reactors $(3.46 \mathrm{~kg}$ with an average $\mathrm{Pu}-239$ content of about $90 \%$, Table 4).

There are a variety of practical implications of dedicated plutonium production campaigns that are not further discussed here. For example, significantly fewer ordinary fuel elements are required to run the reactor than would be expected based on the thermal power of the facility. This is due to the significant energy release in the target material. At the same time, a very large number of target fuel elements, containing a considerable and possibly undeclared uranium inventory, has to be loaded into and discharged from the reactor. This striking discrepancy between requested fuel (low) and core management activities (high) makes covert plutonium production in an adequately safeguarded reactor rather difficult. 


\section{NOTES AND REFERENCES}

1. IAEA safeguards are designed to address some of these proliferation risks, i.e., to detect and deter in a timely way diversion of nuclear material. Safeguards, however, cannot prevent theft or diversion and are ineffective in a breakout-scenario. For almost three decades, experts have therefore emphasized the importance of increasing the inherent proliferation-resistance of the nuclear fuel cycle, a measure that has also been acknowledged by the member states of the IAEA during the International Nuclear Fuel Cycle Evaluation (INFCE, 1978-1980).

2. There are a number of historic precedents that illustrate the practical relevance of both scenarios. The most prominent examples are Israel and India, which have used unsafeguarded facilities (Dimona, Cirus, and Dhruva), all formally classified as research reactors, since the early 1960 s to produce plutonium for their respective weapon programs. Israel destroyed the Iraqi HEU-fueled Osirak reactor, which had been supplied by France, in June 1981 suspecting the intention for covert plutonium production or HEU diversion. In 1991, Iraq had planned a "crash program" to divert safeguarded 80\%enriched fuel from a Soviet-supplied research reactor (IRT-5000) for further enrichment.

3. Dedicated plutonium production in MTR-type reactors, for instance in natural uranium located in special target fuel elements, is not part of the present analysis. For reference purposes, this issue is briefly discussed in an appendix to this article.

4. MTR-type reactors represent the most important class of research reactors today and use enriched uranium in characteristic plate-type fuel elements. The original Material Testing Reactor was designed and built collaboratively by the Oak Ridge and Argonne National Laboratories (ORNL and ANL) and operated from 1952-1970 on the site of the former Idaho National Engineering Laboratory (INEL).

5. All other uranium isotopes have decayed since their primeval endowment having half-lives of less than $10^{8}$ years. As part of the U-238 decay-chain, trace amounts of U-234 $(0.0055 \%)$ are however present in natural uranium, whereas U-236 is artificially produced during irradiation of uranium fuel in nuclear reactors. In the following discussion, the trace constituents U-234 and U-236 are ignored. Similarly, uranium compositions containing significant fractions of U-233, which can be produced via irradiation of thorium-232, are not considered in this article.

6. At the first Atoms for Peace conference held in Geneva in 1955 however, Alvin Weinberg reported that he had "just received information from my country that sample $\mathrm{UO}_{2}$-aluminum 20 per cent enriched fuel elements of the type which will be available to foreign countries have now been tested both in the LITR and in the MTR" (Session 9A, Vol. II, August 12, 1955, p. 430). Although, Weinberg does not use the term LEU in his paper nor in the discussion explicitly, his statements suggest that a policy was already in place distinguishing LEU and HEU. Domestic U.S. research reactors were HEU-fueled at that time. The export of HEU was authorized by the U.S. only in 1958.

7. International Atomic Energy Agency. Safeguards Glossary. 2001 Edition. International Nuclear Verification Series, No. 3. Vienna, 2002, §4.12.

8. IAEA, op. cit., $\S 4.25$ and $\S 4.26$.

9. The following isotopic compositions are used: $1.8 \% \mathrm{Pu}-238,59.0 \% \mathrm{Pu}-239,23.0 \%$ $\mathrm{Pu}-240,12.2 \% \mathrm{Pu}-241$, and $4.0 \% \mathrm{Pu}-242$ for reactor-grade plutonium; $1.2 \% \mathrm{Pu}-238$, 70.9\% $\mathrm{Pu}-239,15.4 \% \mathrm{Pu}-240,10.6 \% \mathrm{Pu}-241$, and $1.9 \% \mathrm{Pu}-242$ for fuel-grade plutonium; 0.05\% Pu-238, 93.6\% Pu-239, 6.0\% Pu-240, 0.3\% Pu-241, and 0.05\% Pu-242 for weapon-grade plutonium.

10. Self-evidently, a low critical mass also reduces the amount of material that has to be produced, diverted, or otherwise acquired. It also facilitates transportation, concealment, etc. of the material. 
11. In addition to spontaneous fission, $(\alpha, n)$-reactions are a secondary source of neutrons. In this case, $\alpha$-particles emitted by uranium or plutonium isotopes may interact with traces of beryllium or oxygen in the nuclear material. Due to the large half-lives of all relevant uranium isotopes, $(\alpha, n)$-reactions can be neglected in the present context. They have to be taken into account, however, for estimates of total neutron emission rates in plutonium. Uranium recovered from spent fuel may contain trace quantities of certain transuranium isotopes with high spontaneous fission rates. See Note 20 for a discussion.

12. MCNP simulations for a highly simplified model of a gun-type weapon conceptually similar to the Hiroshima bomb (cylindrical geometries of projectile and target) predict that the distance the projectile has to travel with the configuration being supercritical is greater than $20 \mathrm{~cm}$. This corresponds to about $0.7 \mathrm{~ms}$ assuming an assembly speed of $300 \mathrm{~m} / \mathrm{s}$. The respective discussion in the Los Alamos Primer quotes muzzle velocities of up to $1000 \mathrm{~m} / \mathrm{s}$, but these require gun weights, which can be considered unrealistically high. See Robert Serber: The Los Alamos Primer. University of California Press, Berkeley, 1992, Section 20.

13. Data taken from J. Magill: Nuclides.net-An Integrated Environment for Computations on Radionuclides and their Radiation. Springer-Verlag, Berlin, 2003.

14. For a spherical configuration, the distance to be traveled by the projectile with the configuration being supercritical roughly increases with $\sqrt[3]{M}$. Using the critical mass values for HEU and LEU from Figure 1, this would correspond to a 2.3-fold increase of the assembly-time.

15. The assumption that the proliferator is relatively unexperienced is plausible because, otherwise, the construction of an implosion-type device would clearly be a preferable option.

16. See Note 21.

17. The isotopics of the irradiated uranium have been determined in cell burnup calculations, which are discussed further below: $81.0 \% \mathrm{U}-235,9.3 \% \mathrm{U}-236$, and $9.7 \%$ $\mathrm{U}-238$. The bare critical mass of this composition is $65 \mathrm{~kg}$ (compared to $53 \mathrm{~kg}$ for WGU).

18. See Serber, op. cit., or J. Carson Mark, "Explosive Properties of Reactor-Grade Plutonium," Science \& Global Security, 4 (1993): 111-128.

19. A. Glaser: Neutronics Calculations Relevant to the Conversion of Research Reactors to Low-Enriched Fuel. Ph.D. Thesis, Department of Physics, Darmstadt University of Technology, 2005. For details on the fundamental neutronics codes, see J. F. Briesmeister (ed.): MCNP - A General Monte Carlo N-Particle Transport Code. Version 4C. LA13709-M, Los Alamos National Laboratory, December 2000; A. G. Croff: A User's Manual for the ORIGEN2 Computer Code. ORNL/TM7175, Oak Ridge National Laboratory, July 1980; and S. Ludwig: "Revision to ORIGEN2_Version 2.2." Transmittal Memo, May 23, 2002 .

20. U-235 burnup corresponds to the total fractional consumption of U-235 including fission, capture, and other processes. Note that the irradiation time is not directly proportional to the burnup of the fuel due to the plutonium buildup and subsequent fission, an effect particularly pronounced for lower enrichment levels. As a consequence, the U-235 consumption per MWd(th) decreases for lower enrichment and higher average burnup of the fuel.

21. If the uranium recovered from the spent fuel is to be used in a gun-type device, strong neutron emitters have to be successfully removed in the purification process. An analysis of typical spent fuel compositions of MTR-type fuel indicate that about 99.99\% of the critical isotopes $\mathrm{Pu}-238, \mathrm{Pu}-240$, and $\mathrm{Cm}-244$ have to be eliminated from 
the uranium stream. This is, for instance, equivalent to a final plutonium-uranium ratio of $10^{-6}$. Benedict el al. confirm that ratios of less than $10^{-8}$ can be achieved with the PUREX-process, if an additional cleanup step is added (p. 487). It is questionable whether a low-tech proliferator could achieve such purification levels. If not, only the fresh fuel would be candidate-material for a crude nuclear device. For a discussion of the PUREX process, see: M. Benedict, T. H. Pigford, and H. W. Levi, Nuclear Chemical Engineering, Second Edition, McGraw-Hill, New York, 1981, pp. 466-514.

22. The spontaneous fission rate is not a meaningful quantity to approximate the weapon-usability of uranium if used with the rapid implosion-type method, which was first invented to circumvent the preinitiation-problem. In general, rates are extremely low compared to those of typical plutonium compositions.

23. It is remarkable that the uranium contribution is the leading proliferation concern for enrichment levels as low as $30 \%$, even though its usability is still strongly suppressed by the weighting factor used in the present analysis.

24. In the previously mentioned 1991 crash program, Iraq had planned to divert safeguarded 80\%-enriched research reactor fuel for further enrichment with a small cascade of centrifuges (49 machines), a strategy equivalent to the present scenario. For such a low number of separating units however, the operation of the enrichment cascade would inevitably be suboptimal and significant mixing losses can be expected. These losses would lead to a moderate increase of the time required to enrich the feed-stock to weapon-grade uranium. For a description of the Iraqi crash program, see D. Albright, F. Berkhout, and W. Walker, Plutonium and Highly Enriched Uranium 1996. World Inventories, Capabilities, and Policies. Stockholm International Peace Research Institute (SIPRI), Oxford University Press, 1997, pp. 344-349.

25. A. de la Garza, G. A. Garrett, and J. E. Murphy, "Multicomponent Isotope Separation in Cascades," Chemical Engineering Science, 15, 1961: 188-209.

26. Independently from the fact that plutonium production increases significantly for very low enrichment levels, such a fuel would be an inferior candidate for modern research reactors. For a specified U-235 inventory, very low-enriched fuel would require a larger core size, which reduces maximum neutron fluxes available for experiments.

27. Federal Ministry of Education and Research (BMBF). Vereinbarung über FRM II vorgestellt. Press release No. 169/2001, October 25, 2001.

28. More recent analyses have shown that an enrichment of about $30 \%$ would be feasible with monolithic fuel and with only minor modifications of the core geometry (Glaser, op. cit.). If some additional design constraints could be relaxed, such as the outer diameter of the fuel element or the power level of the reactor, a conversion to LEU seems feasible without performance loss of the reactor.

29. Nuclear Fuel. "CEA likely to use HEU to start up new test reactor." 29(24) November 22, 2004, p. 1.

30. The following discussion does not assess the feasibility of successfully hiding plutonium production in a safeguarded research reactor. The effectiveness of safeguards to detect covert plutonium production has been addressed, for instance, in M. M. Miller and C. A. Eberhard: The Potential for Upgrading Safeguards at Research Reactors Fueled with Highly Enriched Uranium. Massachusetts Institute of Technology, prepared for the United States Arms Control and Disarmament Agency (ACDA), November 1982; and J. A. Powers: Safeguarding Research Reactors. STR-118 (Draft), International Atomic Energy Agency, March 1983.

31. Both target materials are virtually identical in terms of plutonium buildup, but energy release in natural uranium may be a significant fraction of the total thermal power of the reactor. 


\section{Glaser}

32. The conversion ratio is defined as the number of plutonium atoms produced per U-235 atoms consumed. As listed in Table 4, typical reference values are 1.1-1.2 g(U235)/MWd(th).

33. In the case of a large graphite-moderated natural-uranium-fueled reactor, leakage would be much smaller. This reactor-type achieves conversion ratios of up to 0.8 . Scaled to a $30 \mathrm{MW}$ reactor operated for 300 days per year, this corresponds to an annual plutonium production of more than $8 \mathrm{~kg}$.

34. Miller and Eberhard (op. cit.) consider a generic MTR-type reactor rated at $50 \mathrm{MW}$ and estimate an annual plutonium production of $5-10 \mathrm{~kg}$. 